\title{
Emergency medicine matters: epidemiology of medical pathology and changes in patient outcomes after implementation of a post-graduate training program at a Tertiary Teaching Hospital in Kigali, Rwanda
}

Katelyn Moretti ${ }^{*}$ (D), Doris Lorette Uwamahoro², Sonya Naganathan ${ }^{1}$, Chantal Uwamahoro², Naz Karim', Menales Nkeshimana ${ }^{2}$ and Adam R. Aluisio ${ }^{1}$

\begin{abstract}
Background: Emergency care is a new but growing specialty across Africa where medical conditions have been estimated to account for $92 \%$ of all disability-adjusted life years. This study describes the epidemiology of medical emergencies and the impact of formalized emergency care training on patient outcomes for medical conditions in Rwanda.

Methods: A retrospective cohort study was performed using a database of randomly sampled patients presenting to the emergency center $(\mathrm{EC})$ at the University Teaching Hospital of Kigali. All patients, $>15$ years of age treated for medical emergencies pre- and post-implementation of an Emergency Medicine (EM) residency training program were eligible for inclusion. Patient characteristics and final diagnosis were described by time period (January 2013September 2013 versus September 2015-June 2016). Univariate chi-squared analysis was performed for diagnoses, EC interventions, and all cause EC and inpatient mortality stratified by time period.

Results: A random sample of 1704 met inclusion with 929 patients in the pre-residency time period and 775 patients in the post-implementation period. Demographics, triage vital signs, and shock index were not different between time periods. Most frequent diagnoses included gastrointestinal, infectious disease, and neurologic pathology. Differences by time period in EC management included antibiotic use (37.2\% vs. $42.2 \%, p=0.04)$, vasopressor use (1.9\% vs. 0.5\%, $p=0.01)$, IV crystalloid fluid (IVF) use (55.5\% vs. $47.6 \%, p=0.001)$ and mean IVF administration (2057 ml vs. $2526 \mathrm{ml}, p<0.001)$. EC specific mortality fell from 10.0 to $1.4 \%(p<0.0001)$ across time periods.

(Continued on next page)
\end{abstract}

\footnotetext{
* Correspondence: katelyn_moretti@brown.edu

'Department of Emergency Medicine, Warren Alpert Medical School, Brown University, Providence, USA

Full list of author information is available at the end of the article
}

C C The Author(s). 2021 Open Access This article is licensed under a Creative Commons Attribution 4.0 International License, which permits use, sharing, adaptation, distribution and reproduction in any medium or format, as long as you give appropriate credit to the original author(s) and the source, provide a link to the Creative Commons licence, and indicate if changes were made. The images or other third party material in this article are included in the article's Creative Commons licence, unless indicated otherwise in a credit line to the material. If material is not included in the article's Creative Commons licence and your intended use is not permitted by statutory regulation or exceeds the permitted use, you will need to obtain permission directly from the copyright holder. To view a copy of this licence, visit http://creativecommons.org/licenses/by/4.0/ The Creative Commons Public Domain Dedication waiver (http://creativecommons.org/publicdomain/zero/1.0/) applies to the data made available in this article, unless otherwise stated in a credit line to the data. 
(Continued from previous page)

Conclusions: Mortality rates fell across top medical diagnoses after implementation of an EM residency program. Changes in resuscitation care may explain, in part, this mortality decrease. This study demonstrates that committing to emergency care can potentially have large effects on reducing mortality.

Keywords: Medical pathology, Low-middle income countries, Emergency medicine training, Residency, Rwanda

\section{Introduction}

Health initiatives worldwide have historically focused on primary preventative strategies and communicable disease specific interventions [1]. However, in 2019, The World Health Organization specifically recognized the importance of a functional emergency care system and named it "an essential component of quality care, and that millions of deaths and long-term disabilities could be prevented if emergency care services exist and patients reach them in time." [2]. Even so, a systemic approach to emergency medicine (EM) is often missing despite demonstrations of its necessity [3]. Often, clear data from low- and middle-income countries (LMICs) on the impact of quality emergency care is relegated to a specific disease states and the outcomes from systemic integration of emergency care into the healthcare system is overlooked [4].

While traumatic injuries are often the focus when discussing the need for emergency care, LMICs bear a disproportionate burden of non-traumatic pathology including infectious disease, maternal complications and malnutrition [5]. In addition, as the prevalence of non-communicable diseases (NCDs) increase, their proportional mortality rates are also increasing [6]. In 2011, a consensus conference was held with subSaharan African leaders during which acute care was identified as necessary and underdeveloped [7]. One barrier highlighted was the underreporting of the burden of acute diseases; medical conditions have been estimated to account for $92 \%$ of all disability-adjusted life years across Africa [3].

Rwanda is a LMIC which has identified emergency medicine as a key priority [8]. The first EM residency training program in the country was started at the University Teaching Hospital of Kigali (CHUK) in August 2015. Since the implementation of the emergency care system at CHUK, overall hospital mortality likelihood has fallen by $43 \%$ [9]. While the epidemiology of traumatic pathology has been previously described $[10,11]$, the specific burden from non-traumatic diseases and the impact of the implementation of a system of emergency care on this population remains unknown. In the following analyses, patient characteristics and diagnoses, EM interventions, and patient mortality are quantified and described across pre- and post-residency implementation time periods.

\section{Methods}

This retrospective cohort study was performed using a previously established database out of the University Teaching Hospital of Kigali (CHUK) in Kigali, Rwanda [12]. This hospital represents the primary national public referral center of Rwanda and is an urban, tertiary-care institution with approximately 40 emergency beds and 500 inpatient beds. In August 2015, a 4-year EM residency training program was launched as previously described [8]. This resulted in a model of EM resident staffing with specialist oversight. Additional changes included point-of-care ultrasound, formalized triage, teambased resuscitation, and the implementation of patient acuity zones. No changes were made to resource allocation nor to the physical structure of the department. EMS advice provided by ED physicians may also have been affected by this model, with terminal patients remaining at home or the deceased pronounced in the prehospital setting.

Patients 16 years of age or older presenting to the EC during the time periods of January-September 2013 and September 2015-June 2016 with a primary medical complaint were eligible for inclusion. Data was collected in an interrupted time series to evaluate the effects of implementation of this new residency program [10].

Cases were identified from the CHUK Emergency Database whose creation has been previously described [9, 11-14]. In summary, all EC cases during the study period were identified and linked to corresponding medical records via a multipoint composite index and a random sample of cases were accrued based on month of EC visitation for analysis. Data was then extracted from medical records using a standardized instrument.

\section{Data management}

All patients with an initial triage categorization of medical, age greater than or equal to 15 with a final diagnosis recorded were included and stratified based on time period. Patients were categorized as medical vs. trauma based on clinical data provided from the source charts in which the South Africa Triage Scale was used. The South Africa Triage Scale categorizes patients as trauma vs. non-trauma. Those classified as non-trauma, were coded as medical [15].

Patient characteristics including gender, age, triage vital signs, and shock index were described by time 
period. Primary final diagnosis was categorized by physiologic system. Inpatient and EC deaths were aggregated for overall mortality outcomes. Patients who eloped or were transferred to a different institution were analyzed as survivals.

Subgroup analyses by final diagnosis examined inpatient and EC mortality pre- and post-residency implementation. Selected EC interventions of interest included intravenous (IV) crystalloid administration, blood product transfusion, antibiotic administration, vasopressor administration, use of supplemental oxygen, and intubation and were analyzed as binary (given/not given). All forms of vasopressors aggregated for analysis. IV crystalloids included lactated ringers and normal saline administration. Mean volume of IV crystalloid fluid administration was analyzed among those receiving fluids.

Supplemental oxygen included the following noninvasive methods: nasal cannula, face mask or nonrebreather mask. Intubation was analyzed as binaryperformed and not performed. Triage vital signs are reported as median with interquartile ranges (IQR). Shock index (heart rate divided by systolic blood pressure) was calculated and dichotomized by $\leq 0.9$ and $>0.9$ based on previous studies $[16,17]$.

\section{Data analysis}

Data analysis was performed using STATA version 15.0 (StataCorp.; College Station, USA). Descriptive analysis was performed for the overall cohort stratified by the time period. Variables were described using frequencies with percentages. Final diagnoses were categorized described using frequencies with percentages. Univariate chi-squared analysis was performed comparing pre- and post-residency implementation for all-cause, EC, and inpatient mortality overall and for each of the top 6 final diagnosis categories by time period. Univariate chisquared analysis was performed for EC interventions for each of the top 6 final diagnoses by time period.

\section{Results}

A study sample of 1704 met inclusion criteria. There were 929 cases in the pre-residency time period (January-September 2013) and 775 cases in the postresidency implementation time period (September 2015-June 2016). Of the initial cohort, 83 cases (2.2\%) were excluded for missing data (Fig. 1).

Patient characteristics including gender, age distribution, triage vital signs, and shock index were similar across both time periods (Table 1). In both cohorts,

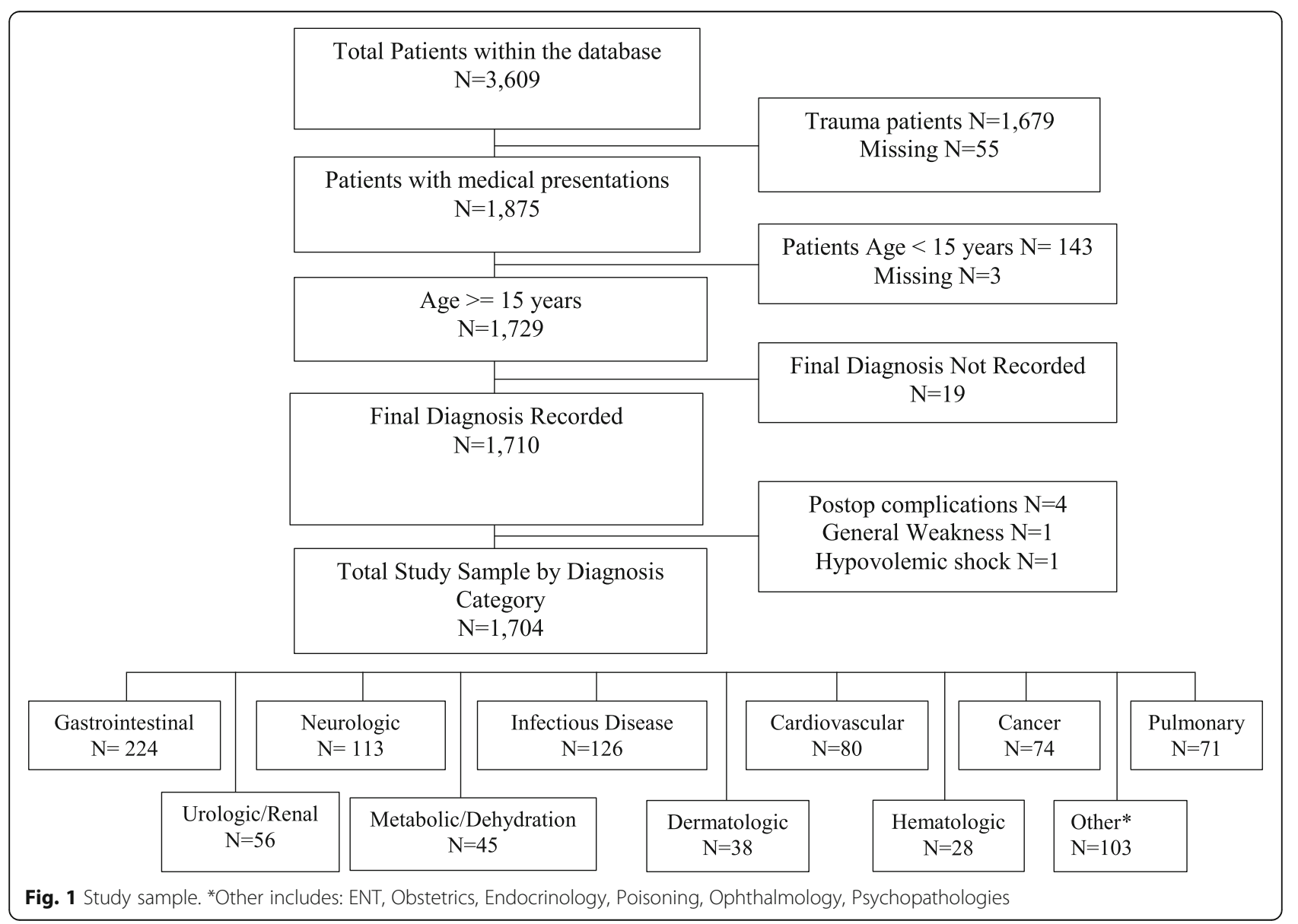


there was a slight male predominance (52.9 and 53.9\%) and the majority of patient presented between the ages of 16 to 44 years (55.4 and 57.6\%) with an equal proportion of shock index greater than 0.9 (29.0 and 27.7\%).

Prevalence of the top 6 systems causing pathology in medical patients was not different between time periods (Fig. 2) and included in decreasing prevalence: gastrointestinal ( $26.3 \%$ vs. $25.4 \%, p=0.69)$, infectious disease (13.6\% vs. $15.6 \%, p=0.23)$, neurologic $(12.2 \%$ vs. $10.3 \%$, $p=0.23)$, pulmonary ( $7.6 \%$ vs. $8.3 \%, p=0.64)$, cardiovascular $(8.6 \%$ vs. $7.0 \%, p=0.21)$, and urologic or renal $(6.0 \%$ vs. $8.3 \%, p=0.07)$. These six categories encompassed $75 \%$ of the total patient cohort.

Differences in EC management observed across the time periods includes increased use of antibiotics (37.2\% vs. $42.2 \%, p=0.04)$ and decreased use of vasopressors $(1.9 \%$ vs. $0.5 \%, p=0.01)$. A decrease in percent patients receiving IV crystalloid fluid resuscitation was noted $(55.5 \%$ vs. $47.6 \%, p=0.001)$. However, mean amount of crystalloid fluids received when administered increased across time periods $(2057 \mathrm{ml}$ vs. $2526 \mathrm{ml}, t$ test $=0.0001$, Table 2). Overall facilities based all-cause patient mortality decreased between time periods $(19.7 \%$ vs. $14.0 \%, p=0.002)$. There was no statistical difference in inpatient mortality. ED specific mortality fell from $10.0 \%$ to $1.4 \%(p<0.0001)$ with statistically decreased ED mortality for patients diagnosed with gastrointestinal, infectious, neurologic, and cardiovascular disease (Table 3).
When ED interventions were analyzed for each of the top 6 diagnosis categories by time period, trends in increasing frequency of antibiotic administration were noted for cases with infectious diseases, neurologic pathology and cancer. However, statistically significant increases were seen only for gastrointestinal pathology ( $40.9 \%$ vs. $50.7 \%, p=0.04)$. A decrease in vasopressor use was seen for gastrointestinal pathology, infectious disease, cardiovascular disease, and cancer, although none were statistically significant. Although only cardiovascular reached statistical significance, a trend toward decreasing frequency of IV fluid administration was noted across the top 5 diagnoses, increasing only in the sixth diagnosis of pulmonary pathology. The mean amount administered increased across all six diagnoses, although only gastrointestinal pathology reached statistical significance.

\section{Discussion}

The top 6 physiologic systems of medical pathologies across both time periods found in the emergency department were gastrointestinal, infectious disease, neurologic, pulmonary, cardiovascular, and urologic or renal. Changes in EC interventions and mortality rates across time periods demonstrate the potential impacts EC care can have on patients with medical pathology. Understanding the overall medical burden of disease allows for targeted disease analyses and interventions that will result in the greatest impact.

Table 1 Patient presenting characteristics, triage vital signs, and shock index by time period (January-September 2013 and September 2015-June 2016)

\begin{tabular}{lll}
\hline & Pre-residency $(\boldsymbol{N}=\mathbf{9 2 9})$ & Post-residency implementation $(\boldsymbol{N}=\mathbf{7 7 5})$ \\
\hline Sex (\%) & $491(52.9)$ & $418(53.9)$ \\
Male & $438(47.2)$ & $357(46.1)$ \\
Female & $0(0)$ & $0(0)$ \\
Missing & & \\
Age (\%) & $41(29,59)$ & $40(28,60)$ \\
Overall median (IQR) & $515(55.4)$ & $446(57.6)$ \\
16-44 & $255(27.5)$ & $182(23.5)$ \\
$45-65$ & $159(17.1)$ & $147(19.0)$ \\
$>=65$ & $0(0)$ & $0(0)$ \\
Missing & & $96(81,112)$ \\
Vital signs, median (IQR) & $98(83,115)$ & $20(18,20)$ \\
Heart rate & $20(20,22)$ & $119(106,135)$ \\
Respiratory rate & $123(107,141)$ & $215(27.7)$ \\
Systolic blood pressure & & $172(22.2)$ \\
Shock index (\%) & $466(50.2)$ & \\
$</=0.9$ & $269(29.0)$ & $388(50.1)$ \\
$>0.9$ & $194(20.0)$ & \\
Missing & & \\
\hline
\end{tabular}




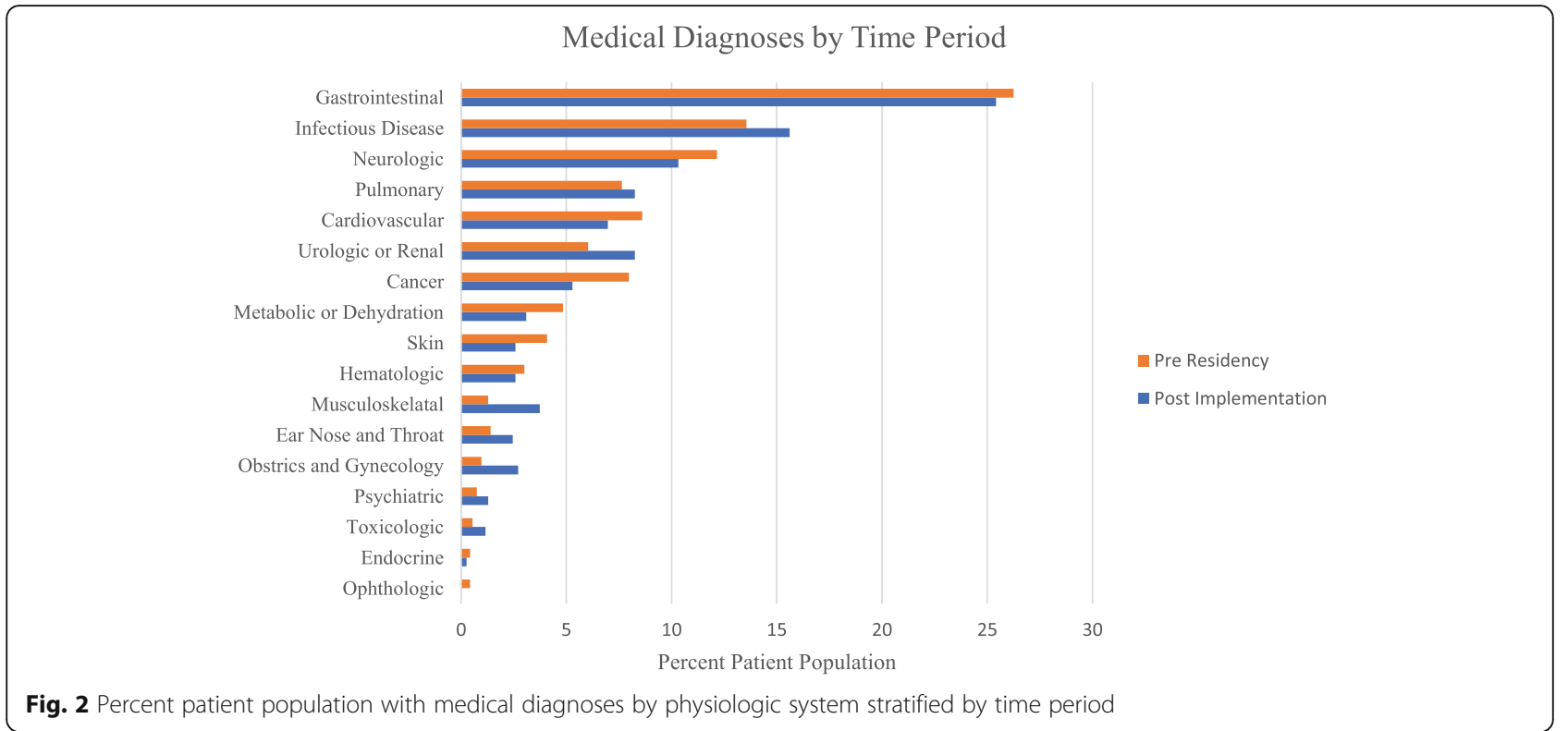

Previous studies examining the burdens of medical pathology amongst EC patients in Africa are limited, with just one additional study identified examining all patients (including pediatrics) presenting to the EC. In a study from Ifakara, Tanzania, infectious disease and trauma were noted as primary diagnoses. However, similar to cardiovascular rates seen in the present data, hypertensive emergency was noted as the leading diagnosis in those $>50$ years of age [18]. Disease-specific studies in Tanzania have noted similarly high rates of cardiovascular and neurologic pathology [19] as well as renal disease [20] and gastrointestinal pathology [21] as seen in this study. Thus, this study helps to establish a foundation of the epidemiology of medical pathology amongst adult patients in LMICs and more specifically, Africa which will facilitate better understanding of care and resource needs in those settings. In addition, the consistency noted with data from Tanzania suggests external validity of results reported here.

After the implementation of an emergency medicine residency, a decrease in overall medical mortality, driven by EC mortality, was seen. The lack of change in inpatient mortality rates suggest these findings are, in fact, driven predominately by impacts during early care delivery in the EC setting. In sub-analyses, EC mortality decreased in the top 5 diagnosis categories. Similar findings of overall decreased mortality rates were seen after institution of an emergency medicine residency program in Tanzania although specific changes in EC management were not described [21].

Specific EC interventions were analyzed across time periods and by systems in order to attempt to assess for management changes that could have contributed to observed decreased mortality. After the initiation of residency training, a more targeted and aggressive use of IV fluids. While fewer patients received intravenous fluids, those that did received a larger amount. An assumed subsequent decrease in the use of vasopressors, oxygen therapy (for neurologic patients), and intubations (for neurologic patients) was found. One potential explanation for these results includes fewer patient complications from IVF administration as the subset of fluid responsive patients were more adequately identified. This trend was maintained in gastrointestinal, infectious disease, neurologic, cardiovascular, and urologic/renal pathologies. However, given small sample sizes within sub-analyses, statistical significance was reached only for increased mean amount IVF for gastrointestinal patients and decreased frequency of IVF for cardiovascular patients. These findings may suggest improved, targeted resuscitation is contributing to improved survival.

In addition, overall use of antibiotics increased in the post-residency time period. This trend was maintained across gastrointestinal, infectious disease, neurologic, pulmonary, and renal although statistical significance was reached only in the first two categories. A decrease was seen in cardiovascular pathologies. When looking at more specific diagnoses within each category (Table 4), all groups with trends in antibiotic increase had infectious causes of top diagnoses. Only cardiovascular, where a decrease in antibiotic use was seen, did not have an infectious cause of a top specific diagnosis. However, the data do not have sufficient detail to fully explore the utilization of all treatments across all medical pathologies and conclusions on causation cannot be drawn.

Given that there was no change in inpatient mortality across time periods, inpatient interventions were not analyzed. 
Table 2 EC interventions stratified by time period and top 6 diagnoses

\begin{tabular}{|c|c|c|c|}
\hline EC intervention & Pre-residency & Post-residency & $\mathrm{Chi}^{2}$ \\
\hline Overall & $N=937$ & $N=780$ & \\
\hline IV crystalloid infusion & $516(55.5)$ & $369(47.6)$ & 0.001 \\
\hline IV fluid amount (ml) & 2057 & 2526 & $t$ test $=0.0001$ \\
\hline Blood products transfused & $88(16.1)$ & $58(14.8)$ & 0.6 \\
\hline Vasopressors & $18(1.9)$ & $4(0.5)$ & 0.01 \\
\hline Intubation & $29(3.1)$ & $13(1.7)$ & 0.06 \\
\hline Antibiotics & $346(37.2)$ & $327(42.2)$ & 0.04 \\
\hline O2 therapy & 169 (18.2) & $113(14.6)$ & 0.046 \\
\hline Gastrointestinal & $N=244$ & $N=197$ & \\
\hline IV crystalloid infusion & $169(69.3)$ & $125(63.5)$ & 0.2 \\
\hline IV fluid amount (ml) & 2784.5 & 3266.8 & $t$ test $=0.04$ \\
\hline Blood products transfused & $20(8.2)$ & $12(6.1)$ & 0.4 \\
\hline Vasopressors & $4(1.6)$ & $1(0.5)$ & 0.3 \\
\hline Intubation & $3(1.2)$ & $2(1.0)$ & 0.8 \\
\hline Antibiotics & $100(40.9)$ & $100(50.7)$ & 0.04 \\
\hline O2 therapy & $20(8.2)$ & $12(6.1)$ & 0.4 \\
\hline Infectious disease & $N=126$ & $N=121$ & \\
\hline IV crystalloid infusion & 79 (62.7) & $62(51.2)$ & 0.07 \\
\hline IV fluid amount (ml) & 2033.8 & 2250 & $t$ test $=0.5$ \\
\hline Blood products transfused & $12(9.5)$ & $8(6.6)$ & 0.4 \\
\hline Vasopressors & $3(2.4)$ & $0(0)$ & 0.09 \\
\hline Intubation & $4(3.2)$ & $5(4.1)$ & 0.7 \\
\hline Antibiotics & $75(59.5)$ & $74(61.2)$ & 0.8 \\
\hline O2 therapy & $35(27.8)$ & $16(13.2)$ & 0.005 \\
\hline Neurologic & $N=113$ & $N=80$ & \\
\hline IV crystalloid infusion & $62(54.9)$ & $37(46.3)$ & 0.4 \\
\hline IV fluid amount (ml) & 1416 & 1595 & $t$ test $=0.5$ \\
\hline Blood products transfused & $3(2.7)$ & $0(0)$ & 0.2 \\
\hline Vasopressors & $1(0.9)$ & $1(1.25)$ & 0.8 \\
\hline Intubation & $13(11.5)$ & $2(2.5)$ & 0.02 \\
\hline Antibiotics & $35(31.0)$ & $26(32.5)$ & 0.8 \\
\hline O2 therapy & $29(25.7)$ & $13(16.3)$ & 0.1 \\
\hline Pulmonary & $N=71$ & $N=64$ & \\
\hline IV crystalloid infusion & $29(40.9)$ & $27(42.2)$ & 0.9 \\
\hline IV fluid amount (ml) & 1574 & 1761 & $t$ test $=0.5$ \\
\hline Blood products transfused & $1(1.4)$ & $2(3.1)$ & 0.5 \\
\hline Vasopressors & $0(0)$ & $0(0)$ & \\
\hline Intubation & $2(2.8)$ & $1(1.6)$ & 0.6 \\
\hline Antibiotics & $24(33.8)$ & $30(46.9)$ & 0.1 \\
\hline O2 therapy & $27(38.0)$ & $28(43.8)$ & 0.5 \\
\hline Cardiovascular & $N=80$ & $N=54$ & \\
\hline IV crystalloid infusion & $32(40.0)$ & $10(18.5)$ & 0.009 \\
\hline IV fluid amount & 1629 & 2700 & $t$ test $=0.2$ \\
\hline Blood products transfused & $5(6.2)$ & $4(7.4)$ & 0.79 \\
\hline
\end{tabular}


Table 2 EC interventions stratified by time period and top 6 diagnoses (Continued)

\begin{tabular}{llll}
\hline EC intervention & Pre-residency & Post-residency & Chi $^{\mathbf{2}}$ \\
\hline Vasopressors & $6(0.4)$ & $2(3.7)$ & 0.4 \\
Intubation & $2(2.5)$ & $1(1.9)$ & 0.8 \\
Antibiotics & $18(22.5)$ & $9(16.7)$ & 0.4 \\
O2 therapy & $30(37.5)$ & $19(35.2)$ & $\mathbf{N}=\mathbf{6 4}$ \\
Urologic or renal & $\mathbf{N}=\mathbf{5 6}$ & $15(23.4)$ & 0.8 \\
IV crystalloid infusion & $18(32.1)$ & 1844 & 0.29 \\
IV fluid amount & 1233 & $2(3.1)$ & $t$ test $=0.17$ \\
Blood products transfused & $4(7.1)$ & $0(0)$ & 0.31 \\
Vasopressors & $2(3.6)$ & $0(0)$ & 0.13 \\
Intubation & $1(1.8)$ & $18(28.1)$ & 0.28 \\
Antibiotics & $11(19.6)$ & $9(14.1)$ & 0.28 \\
O2 therapy & $5(8.9)$ & 0.38 \\
\hline
\end{tabular}

\section{Limitations}

Given the retrospective nature of the chart review, a proportion of cases were deemed ineligible due to missing data which may introduce bias. However, records are assumed to be missing at random and should therefore represent limited bias. In addition, the retrospective nature of the dataset does not allow for analysis of causality.

While illness severity was evaluated with triage vital signs and shock index, the dynamics of patient acuity

Table 3 All-cause, emergency center, and inpatient mortality stratified by time period

\begin{tabular}{|c|c|c|c|}
\hline All-cause mortality & Pre-residency $(N=929)$ & $\begin{array}{l}\text { Post-residency } \\
\text { implementation }(N=775)\end{array}$ & $\mathrm{Chi}^{2}$ \\
\hline Overall & $170(19.9)$ & $97(14.0)$ & 0.002 \\
\hline Gastrointestinal & $29(12.8)$ & $18(9.9)$ & 0.4 \\
\hline Infectious disease & $37(30.0)$ & $23(22.1)$ & 0.2 \\
\hline Neurologic & $24(24.0)$ & $12(12.1)$ & 0.3 \\
\hline Cardiovascular & $18(25.4)$ & $9(18.4)$ & 0.4 \\
\hline Cancer & $23(32.4)$ & $17(42.5)$ & 0.3 \\
\hline Pulmonary & $14(22.6)$ & $7(13.2)$ & 0.2 \\
\hline \multicolumn{4}{|l|}{ EC mortality } \\
\hline Overall & $86(10.0)$ & $10(1.4)$ & $<0.0001$ \\
\hline Gastrointestinal & $14(6.2)$ & $1(0.6)$ & 0.003 \\
\hline Infectious disease & $19(15.5)$ & $5(4.8)$ & 0.009 \\
\hline Neurologic & $15(14.9)$ & $0(0)$ & 0.001 \\
\hline Cardiovascular & $12(16.9)$ & $1(2.0)$ & 0.009 \\
\hline Cancer & $5(8.1)$ & $1(1.9)$ & 0.1 \\
\hline Pulmonary & $5(6.9)$ & $2(5.0)$ & 0.7 \\
\hline Inpatient mortality ${ }^{a}$ & $N=522$ & $N=539$ & \\
\hline Overall & $84(16.1)$ & $87(16.1)$ & 1.0 \\
\hline Gastrointestinal & $15(10.9)$ & $17(12.0)$ & 0.8 \\
\hline Infectious disease & $18(22.5)$ & $18(24.3)$ & 0.8 \\
\hline Neurologic & $9(15.3)$ & $12(21.1)$ & 0.4 \\
\hline Pulmonary & $9(36.0)$ & $6(16.7)$ & 0.1 \\
\hline Cardiovascular & $6(14.6)$ & $8(18.2)$ & 0.7 \\
\hline Urologic or renal & $3(9.1)$ & $5(12.5)$ & 0.6 \\
\hline
\end{tabular}

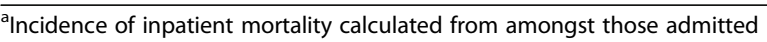


Table 4 Top 5 specific diagnoses within the top 6 diagnosis categories.

\begin{tabular}{lll}
\hline Gastrointestinal & Infectious disease & Neurologic \\
Intestinal obstruction (20.7\%) & Malaria (29.8\%) & Stroke (ischemic or hemorrhagic) (32.9\%) \\
Gastritis/gastric ulcer (13.4\%) & Tuberculosis (27.7\%) & Meningitis/encephalitis (15.1\%) \\
Acute abdomen/peritonitis (12.3\%) & HIV/AIDS-related illness (20.8\%) & Headache (13.5\%) \\
Hernia (8.2\%) & Sepsis (unknown source) (9.4\%) & Seizure (7.8\%) \\
Cirrhosis (5.5\%) & Other (3.8\%) & Other (7.3\%) \\
Pulmonary & Cardiovascular & Urologic/renal \\
Asthma/COPD (41.5\%) & Acute heart failure (34.2\%) & Chronic kidney failure with \\
Pneumonia (28.9\%) & acute exacerbation (21.7\%) \\
Pulmonary effusion (8.9\%) & Hypertension/hypertensive emergency (33.3\%) & Urinary tract infection (20.0\%) \\
Pulmonary embolism (5.2\%) & Dilated cardiomyopathy (10.3\%) & Acute kidney injury (10.0\%) \\
Other (5.2\%) & Valvular disease (5.1\%) & Benign prostatic hypertrophy (7.5\%) \\
\hline
\end{tabular}

were not captured, and confounding is possible. In addition, while categories of patient diagnoses were identified, specific patient pathologies were not examined in relationship to changing management given small observed numbers. Future studies will further evaluate specific diagnoses within leading categories of non-traumatic pathology.

Given the nature of the data, only specific interventions and outcomes were able to be analyzed. Other implementations during the residency such as a triage system, bedside point of care ultrasound and procedural training may be contributing to mortality decreases post-residency implementation. Additional cofounders may also be present. During this time, the Ministry of Health supported similar program development within internal medicine, surgery and anesthesia. Thus, time to consultant intervention and consultant practices may have changed [22]. While mortality rates fell in Rwandan Hospitals during the time of this study, the magnitude of change was greater within this cohort suggesting interventions intrinsic to the department outlined above were contributing to the observed outcomes [23].

Medical disease accounts for the majority of pathology across Africa. However, it remains poorly described. Understanding the distribution of medical pathology by physiologic system allows for more impactful patientcentered research. In addition, while emergency medicine residency training is now accepted in high-income countries, the emergency medicine specialty remains rare or non-existent in LMIC [24]. However, in this study, a formalized emergency medicine program appears to have improved medical patient outcomes, potentially from targeted, aggressive fluid resuscitation. Results reported here add to the growing compendium of data demonstrating that emergency medicine and acute care should be viewed as a necessity, not a luxury.
Source of financial support

Brown Emergency Physicians, Inc.

Authors' contributions

ARA conceived the study and supervised the conduct of data analysis. KM developed the statistical plan and analyzed the data. All authors took part in drafting and revising the manuscript. KM takes responsibility for the manuscript in its entirety. The author(s) read and approved the final manuscript

Availability of data and materials

The datasets generated and analyzed during the current study are not publicly available due to patient confidentiality but are available from the corresponding author on reasonable request.

\section{Competing interests}

The authors have no competing interests to declare. All authors had full access to all study data and had final responsibility for the decision to submit for publication. The content of this manuscript is solely the responsibility of the authors and does not necessarily represent the views of any affiliated academic organizations.

\section{Author details}

'Department of Emergency Medicine, Warren Alpert Medical School, Brown University, Providence, USA. ²Department of Anesthesia, Emergency

Medicine and Critical Care, University of Rwanda, Kigali, Rwanda.

Received: 16 October 2020 Accepted: 5 January 2021

Published online: 21 January 2021

References

1. Farmer PE, Kim JY. Surgery and Global Health: a view from beyond the OR. World J Surg. 2008:32(4):533-6.

2. World Health assembly update, 25 May 2019. https://www.who.int/newsroom/detail/25-05-2019-world-health-assembly-update Accessed: 24 Sep 2020

3. Chang CY, Abujaber S, Reynolds TA, Camargo CA, Obermeyer Z. Burden of emergency conditions and emergency care utilization: new estimates from 40 countries. Emerg Med J. 2016:33(11):794-800.

4. Hsia R, Razzak J, Tsai AC, Hirshon JM. Placing emergency care on the global agenda. Ann Emerg Med. 2010;56(2):142-9.

5. Lozano R, Naghavi M, Foreman K, et al. Global and regional mortality from 235 causes of death for 20 age groups in 1990 and 2010: a systematic analysis for the Global Burden of Disease Study 2010. The Lancet. 2012; 380(9859):2095-128.

6. WHO. Global status report on noncommunicable diseases. Geneva: WHO; 2010. http://www.who.int/nmh/publications/ncd_report2010/en/ Accessed: 13 Jul 2019

7. Calvello E, Reynolds T, Hirshon JM, et al. Emergency care in sub-Saharan Africa: results of a consensus conference. Afr J Emerg Med. 2013;3(1):42-8. 
8. Mbanjumucyo G, DeVos E, Pulfrey S, Epino HM. State of emergency medicine in Rwanda 2015: an innovative trainee and trainer model. Int J Emerg Med. 2015;8:20.

9. Aluisio $A R$, Barry MA, Martin KD, et al. Impact of emergency medicine training implementation on mortality outcomes in Kigali, Rwanda: an interrupted time-series study. Afr J Emerg Med. 2014;9(1):14-20.

10. Lise M. Gender differences in patterns of injuries and trauma in emergency department at Kigali university teaching hospital, Rwanda. 2019; http://dr.ur. ac.rw/handle/123456789/787 Accessed: 29 Jun 2020

11. Mbanjumucyo G, George N, Kearney A, et al. Epidemiology of injuries and outcomes among trauma patients receiving prehospital care at a tertiary teaching hospital in Kigali, Rwanda. Afr J Emerg Med. 2016;6(4):191-7.

12. Kearney AS, Kabeja LM, George N, et al. Development of a trauma and emergency database in Kigali, Rwanda. Afr J Emerg Med. 2016;6(4):185-90.

13. Aluisio AR, Umuhire OF, Mbanjumucyo G, et al. Epidemiologic characteristics of pediatric trauma patients receiving prehospital care in Kigali, Rwanda. Pediatr Emerg Care. 2019;35(9):630-6.

14. Aluisio AR, Garbern $\mathrm{S}$, Wiskel T, et al. Mortality outcomes based on ED qSOFA score and HIV status in a developing low income country. Am J Emerg Med. 2018:36(11):2010-9.

15. Massaut J, Valles $P$, Ghismonde A, et al. The modified South African triage scale system for mortality prediction in resource-constrained emergency surgical centers: a retrospective cohort study. BMC Health Serv Res. 2017; 17(1):594 [cited 30 Nov 2020];17. Available from: https://www.ncbinlm.nih. gov/pmc/articles/PMC5569494/.

16. Heffner AC, Swords DS, Neale MN, Jones AE. Incidence and factors associated with cardiac arrest complicating emergency airway management. Resuscitation. 2013;84(11):1500-4.

17. Cannon CM, Braxton CC, Kling-Smith M, Mahnken JD, Carlton E, Moncure M. Utility of the shock index in predicting mortality in traumatically injured patients. J Trauma. 2009;67(6):1426-30.

18. Mchomvu E, Mbunda G, Simon N, et al. Diagnoses made in an emergency department in rural sub-Saharan Africa. Swiss Med Wkly. 2019;149:w20018 https://doi.emh.ch/smw.2019.20018 Accessed on: 29 Jul 2020.

19. Hertz JT, Sakita FM, Limkakeng AT, et al. The burden of acute coronary syndrome, heart failure, and stroke among emergency department admissions in Tanzania: a retrospective observational study. Afr J Emerg Med. 2019;9(4):180-4.

20. Sylvanus E, Sawe HR, Muhanuzi B, et al. Profile and outcome of patients with emergency complications of renal failure presenting to an urban emergency department of a tertiary hospital in Tanzania. BMC Emerg Med. 2019;19(1):11.

21. Mjema KM, Sawe HR, Kulola I, et al. Aetiologies and outcomes of patients with abdominal pain presenting to an emergency department of a tertiary hospital in Tanzania: a prospective cohort study. BMC Gastroenterol. 2020; 20:173.

22. Binagwaho A, Kyamanywa P, Farmer PE, et al. The human resources for health program in Rwanda-a new partnership. N Engl J Med. 2013;369(21): 2054-9.

23. Aluisio AR, Barry MA, Martin KD, et al. Impact of emergency medicine training implementation on mortality outcomes in Kigali, Rwanda: an interrupted time-series study. Afr J Emerg Med. 2019;9(1):14-20.

24. Nowacki AK, Landes M, Azazh A, Ritchie LMP. A review of published literature on emergency medicine training programs in low- and middleincome countries. Int J Emerg Med. 2013;6:26.

\section{Publisher's Note}

Springer Nature remains neutral with regard to jurisdictional claims in published maps and institutional affiliations.

Ready to submit your research? Choose BMC and benefit from:

- fast, convenient online submission

- thorough peer review by experienced researchers in your field

- rapid publication on acceptance

- support for research data, including large and complex data types

- gold Open Access which fosters wider collaboration and increased citations

- maximum visibility for your research: over $100 \mathrm{M}$ website views per year

At $\mathrm{BMC}$, research is always in progress.

Learn more biomedcentral.com/submissions 